\title{
FINE STRUCTURAL ANALYSIS OF UNPRODUCTIVE AND LOW- PRODUCTIVE CELLS RESULTING ON CULTURED RSIV (IN VITRO)
}

\author{
Ketut Mahardika")\# and Teruo Miyazaki**) \\ ") Research and Development Institute for Mariculture, Gondol, Bali \\ *a) Graduate School of Bioresources, Mie University, Tsu, Mie 514-8507, Japan \\ (Received 7 November 2013; Final revised 8 September 2014; \\ Accepted 10 November 2014)
}

\begin{abstract}
Red seabream iridovirus (RSIV) has been known to induce enlarged cells and inclusion body bearing cells (IBCs) allowing virus particles to propagate within viral assembly site (VAS) in the cell cytoplasm. The aim of this study was to evaluate fine structural analysis of unproductive and low-productive cells resulting on RSIV-infected cultured grunt fin (GF) cells. GF cells were treated with semi purified RSIV, and incubated for 614 days post cultured. The cellular enlargement were harvested, processed, and analysis under electron microscopy. Electron microscopy revealed four types of cells that were productive enlarged cells and productive IBCs which were allowing propagation of virus particles within its cytoplasm, and unproductive enlarged cells and IBCs without virus particles. Most of them were unproductive enlarged cells $(80,71 \%-98,20 \%)$. Unproductive enlarged cell had a nucleus with enlarged cytoplasm without production of VAS with virus propagation. While, unproductive IBC had an inclusion body that was delimited from the host-cell cytoplasm by a thin membranous boundary, and was developed without virus propagation. On the other hand, lowproductive enlarged cells and IBCs contained a few number of virus particles or tubule-like structures. Therefore, the number of low-productive enlarged cells and IBCs were only a few (about 0\%-14\% from a total of percent productive enlarged cells and IBCs), these cells were classified into types of productive enlarged cells and IBCs. These results sugested that the unproductive and low-productive enlarged cells and IBCs were the results of RSIV-infected GF cells which failed to produce virus particles due to incapacity of RSIV virus it self and or the ability of GF cells to inhibit virus multiplication within VAS.
\end{abstract}

KEYWORDS: RSIV, GF cells, unproductive, low-productive, IBCs, enlarged cells

\section{INTRODUCTION}

The members of two genera within the family Iridoviridae (Megalocytivirus and Ranavirus) have been noted previously to be the most serious infections in fish culture. Megalocytiviruses i.e., red seabream iridovirus (RSIV), rock bream iridovirus (RBIV), Taiwan grouper iridovirus (TGIV), dwarf gourami iridovirus (DGIV), grouper sleepy disease iridovirus (GSDIV), African lampeye iridovirus (ALIV), sea bass iridovirus (SBIV), and infectious spleen and kidney necrosis virus (ISKNV) infect a wide variety of marine and freshwater fish in Southeast Asia,

\# Corresponding author. Research and Development Institute for Mariculture, Jl. Br. Gondol, Kec. Gerokgak, Kab. Buleleng, Kotak Pos 140, Singaraja, Bali 81101 , Indonesia. Tel.: +62 36292278 E-mail: kmahardika@yahoo.com 
including several species that are widely used in aquaculture (Nakajima et al., 1998; Chinchar et al., 2005). Outbreaks in these settings can be extensive, with mortalities approaching $100 \%$ (He et al., 2000). The reasons for the explosive nature of recent outbreaks are not known, but may reflect one or more events, including the introduction of a novel pathogen into populations of susceptible fish species, ease of disease transmission among intensively cultured fish, or increased susceptibility to viral disease in immunologically stressed populations (Wiliam et al., 2005).

Megalocytivirus has been known to be cultivated in some cultured cell (in vivo) such as BF-2 (bluegill fry-2), GF (grunt fin), CHSE-214, FHM, JSKG, KRE-3, KRE (a hybrid of kelp and red spotted grouper embryo), RTG-2 and YTF cell lines (Nakajima \& Sorimachi, 1994; Imajoh et al., 2004; Chou et al., 1998). However, BF-2, GF and KRE cell lines were demonstrated to be optimal for Megalocytivirus infection and proliferation (Nakajima \& Sorimachi, 1994; Imajoh et al., 2004; Mahardika \& Miyazaki, 2009). Under light microscopy, a typical cytopathic effect (CPE) is characterized by cell rounded and enlargement. The electron microscopic features of infected rounded-enlargement cells revealed inclusion body-bearing cells (IBCs) and enlarged cells with a virus assembly site serving in propagation of virus particles (Mahardika \& Miyazaki, 2009). Rounded-enlargement cells were divided into three types of cells i.e. enlarged cell containing many mature virions, enlarged cell containing small number of virions and enlarged cell containing many immature virions. The number of enlarged cells containing many mature virions were dominant (Mahardika \& Miyazaki, 2010; Mahardika, 2013). However, cultured RSIV in GF cells was not performed only productive rounded-enlargement cells and IBCs which revealed propagation of viral particles, it was also performed unproductive rounded-enlargement cells without virus particles within its cytoplasm. Most of researchers just focused on infected cells that produced virus particles, because they assumed that unproductive cells are a side effect of cultured virus in the cultured cells (in vitro). However, the unproductive cells are in fact the result of cultured RSIV in cultured cells. Every culture in the amount of virus although many viruses will surely not all cells produce large amounts of virus in the cells but also contain cells even resulting fewer viral particles or no virus within it. There- fore, it is important to provide a detailed fine structural analysis of the cell-virus interactions in vitro. This paper described fine structural analysis of cells which contained fewer viral particles (low-productive enlarged cells) and no viral particles within it (unproductive enlarged cells).

\section{MATERIAL AND METHODS}

\section{Cell Culture}

Grunt fin (GF) cells were used in this study. GF cells were grown in $25 \mathrm{~cm}^{2}$ cell culture flasks at $25^{\circ} \mathrm{C}$ until confluent in Eagle's minimum essential medium (MEM: Nissui, Japan) supplemented with $2 \%$ fetal bovine serum (FBS: Sigma, USA), L-glutamine, and buffered with $\mathrm{NaHCO}_{3}$ to $\mathrm{pH}$ 7.2-7.4, respectively.

\section{Virus Inoculum}

In the present study, spleen homogenates for virus culture, which were prepared from red seabream caught in a mariculture farm in Mie Prefecture, Japan were used. The substances derived from spleen tissues of the virions were removed by washing them in MEM-2 using ultracentrifugation as well as procedure which was previously discribed by Mahardika \& Miyazaki (2009).

\section{Virus Culture}

For virus culture, 6 flask containing 60\%$70 \%$ confluent monolayers of GF cells prepared 24 hours previously were infected with RSIV inoculum at a multiplicity of infection (MOI) of 0.1 , absorbed for $1 \mathrm{~h}$ at $25^{\circ} \mathrm{C}$, and then fresh EMEM-2 was added. Another monolayer GF cells was treated with a spleen homogenate of healthy red seabream as mock-infected GF cells. Treated cells were incubated for 6,7 , 10 , and 14 days post cultured ( $\mathrm{dpc}$ ), and harvested by applaud.

\section{Inverted Microscopic Observation}

Conditions of GF cells that are infected with virus RSIV observed under an inverted microscope every day. Any changes (cytophatic effect/CPE) that occur are recorded and when the $C P E$ reached maximum then the cells were harvested. In this study, performed cell harvester when the CPE was maximum (6-7 dpc) and when the number of cells undergoing changes began to decline due to cell lysis (10$14 \mathrm{dpc}$ ) as the time of harvesting that has been 
presented in our previous publications (Mahardika \& Miyazaki, 2009; 2010).

\section{Electron Microscopy (EM)}

For transmission electron microscopy, $4 \mathrm{~mL}$ of harvested medium containing RSIV-infected GF cells were centrifuged at 1,200 $\times \mathrm{g}$ for 10 min. The obtained pellets were fixed with $70 \%$ Karnovsky's solution, post-fixed in $1 \% \mathrm{OsO}_{4}$ dehydrated stepwise in a graded series of ethanol and embedded in Epon-812. The blocks were sectioned on Leica Ultracutmicrotome. Ultra-thin sections were placed on grids, and then stained with $4 \%$ uranyl acetate and Reynolds lead citrate. The stained grids were examined with a H-7,000 electron microscopy at $75 \mathrm{kV}$.

\section{EM Analysis}

Round-enlarged cells which contained on 20-25 observed-areas within $1,000 \mu \mathrm{m}^{2}$ of the semi-thin section per a sample were examined. These cells were counted at an instrument magnification of $5,000 x$ to $10,000 x$. The cells with virions were divided into three groups i.e. enlarged cells with virions, IBCs, and small round cells with virions.

\section{RESULTS AND DISCUSSION}

\section{Inverted Microscopic Observation}

In the present study, a RSIV harvested culture in GF cells at 6-7 dpc were observed the cytopathic effect as rounded-enlargement cells mostly separated from the monolayer. The rounded-enlargement cells look like floating in culture medium. However, RSIV did not infect all of GF cells, some of GF cells still devel- oped monolayer which it showed from confluent GF cells in the bottom of the flask. The number of floating cells decreased following time incubation ( $10 \& 14 \mathrm{dpc}$ ) which caused by cellular fragmentation.

\section{EM Analysis}

On 6 and 7 days post RSIV culture, the cellular revealed rounded enlargement cells and inclusion body bearing cells (IBCs). Enlarged cells were divided into two types of cells that i.e. productive enlarged cell which allowed virus propagation within the intracytoplasmic virus assembly site (VAS) (Figure 1A \& D) as completely reported in our previous study (Mahardika \& Miyazaki, 2009), and unproductive enlarged cell without virus assembly within its cytoplasmic (Table 1, Figure 1A-2A). Most of them were unproductive enlarged cells (80.51\%-98.20\%), unproductive enlarged cell had a small nuclei within enlarged cytoplasm. The nucleus had poor hetero-chromatin and did not contain granules which suspected as viral genes (Figure 1A, B, C, \& 2A). The nucleus remained until the cell lysis. Cell cytoplasm contains many mitochondria, ribosome, and reticulum endoplasm, but it was not accompanied by production of VAS with virus propagation.

In cell cytoplasmic also did not reveal any rough or smooth granules as it was observed in enlarged cell that contains a virus asembly. Unproductive enlarged cell was always produced in every cultured of RSIV and in excess of the number of enlarged cells containing the virus. However, the structure and size of unproductive enlarged cell was much different than normal GF cell (Figure 3D). Unproductive

Table 1. Electron microscopic cell count of rounded enlarged cells and IBCs resulting on cultured RSIV in GF cells, in vitro

\begin{tabular}{lccccccc}
\hline \multirow{2}{*}{ Samples } & \multirow{2}{*}{$\begin{array}{c}\text { Total } \\
\text { cells }\end{array}$} & \multicolumn{2}{c}{ Enlarged cells } & & \multicolumn{2}{c}{ IBCs } \\
& observed & Productive & Unproductive & & Product ive & Unproductive \\
\hline Cultured-RSIV at $6 \mathrm{dpc}$ (Flask 1) & 723 cells & $70(9.68 \%)$ & $598(82.71 \%)$ & & $17(2.35 \%)$ & $38(5.26 \%)$ \\
Cultured-RSIV at $6 \mathrm{dpc}$ (Flask 2) & 554 cells & $72(13.0 \%)$ & $446(80.51 \%)$ & & $8(1.44 \%)$ & $28(5.05 \%)$ \\
Cultured-RSIV at $7 \mathrm{dpc}$ & 612 cells & $88(14.38 \%)$ & $510(83.34 \%)$ & & $7(1.14 \%)$ & $7(1.14 \%)$ \\
Cultured-RSIV at 10 dpc & 578 cells & $23(3.98 \%)$ & $551(95.33 \%)$ & & 0 & $4(0.69 \%)$ \\
Cultured-RSIV at 14 dpc & 222 cells & $4(1.80 \%)$ & $218(98.20 \%)$ & & 0 & 0 \\
\hline
\end{tabular}

Low-productive enlarged cells and low-productive IBCs were included in productive enlarged cells and IBCs. Cellular fragmentations were counted out as. Dpc: day post cultured. 


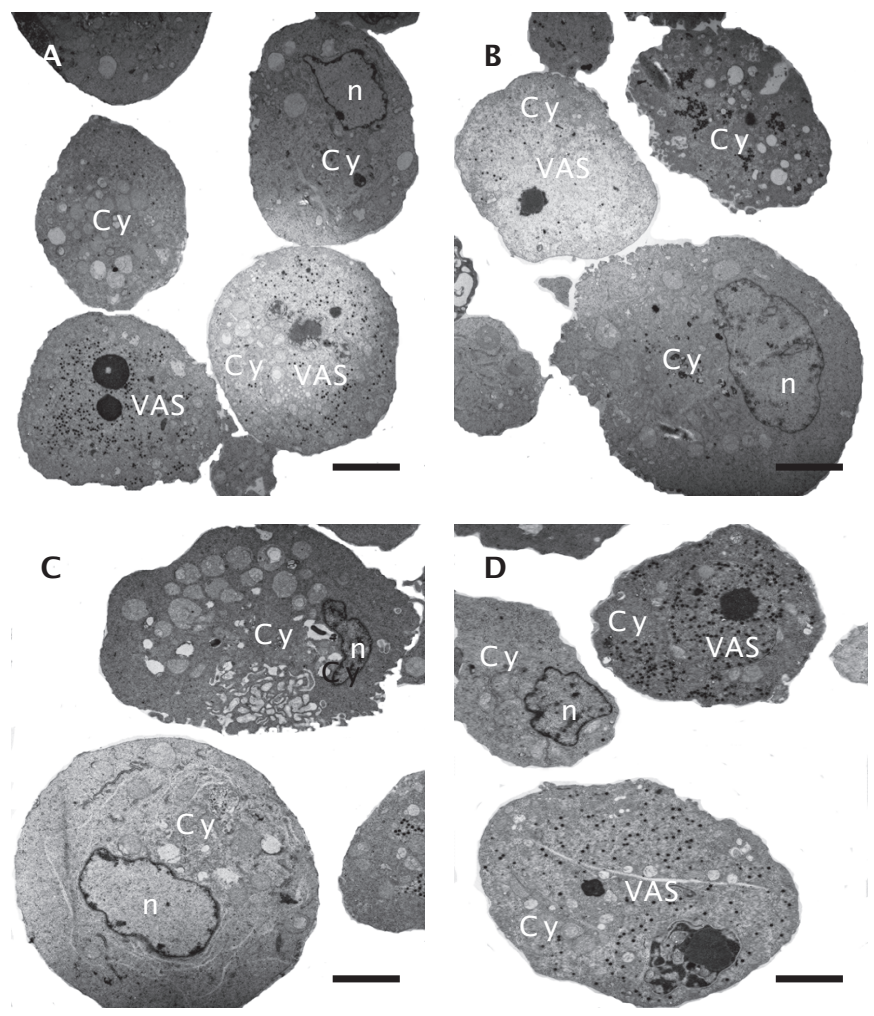

Figure 1. Electron microscopy of RSIV-infected GF cells. (A) two productive enlarged cells contained many propagating virions within VAS (under site), and two unproductive enlarged cells were developed without viral particles (upper site) (scale bar $=2,700 \mathrm{~nm}$ ); (B) a low-productive enlarged cells contained very few number of viral particles within VAS (left-upper), and unproductive enlarged cells with enlarged cytoplasm and nucleus (under) (scale bar = 2,600 nm); (C) two unproductive enlarged cells developed with abundance mitochondria without viral particles (scale bar $=2,000 \mathrm{~nm}$ ); (D) two productive enlarged cells developed with huge number of virions within VAS (scale bar $=2,200 \mathrm{~nm}$ ). Cy: cytoplasm, $\mathrm{n}$ : nucleus, VAS: viral asembly site

enlarged cells became lysis following time incubation similar as those in producive enlarged cells. In lysis procces, unproductive enlarged cell firstly displayed formation of the intracytoplasmic vacuoles which was observed at 7 days post RSIV-cultured. Some of these cells displayed degeneration and fragmentation of the intracytoplasmic organelles. The number of cells that fragmented increased at days 10 and 14 post RSIV-cultured resulting in the decrease of number of productive and unproductive enlarged cells (Table 1). On the other hand, low-productive enlarged cells which contained small number of viral particles (Figure 2B) and enlarged cells containing tubule like structures (Figure 2C) showed their nuclei frag- mented and mostly assimilated with the cytoplasm. Fragmented nuclei was followed by the release of viral gen into the cytoplasm. However, virus particles failed to propagate in the VAS, resulting on small number of virus particles and tubular like-structures formed within VAS. The structure of this cell was similar as these seen as enlarged cells allowed a large number of virions propagated within VAS (Figure 1D).

Second type of cell could also be divided into two types of cells i.e. productive IBCs with allowing propagation of the virus within the VAS and unproductive IBCs without allowing viral particles to be propagated within VAS of 

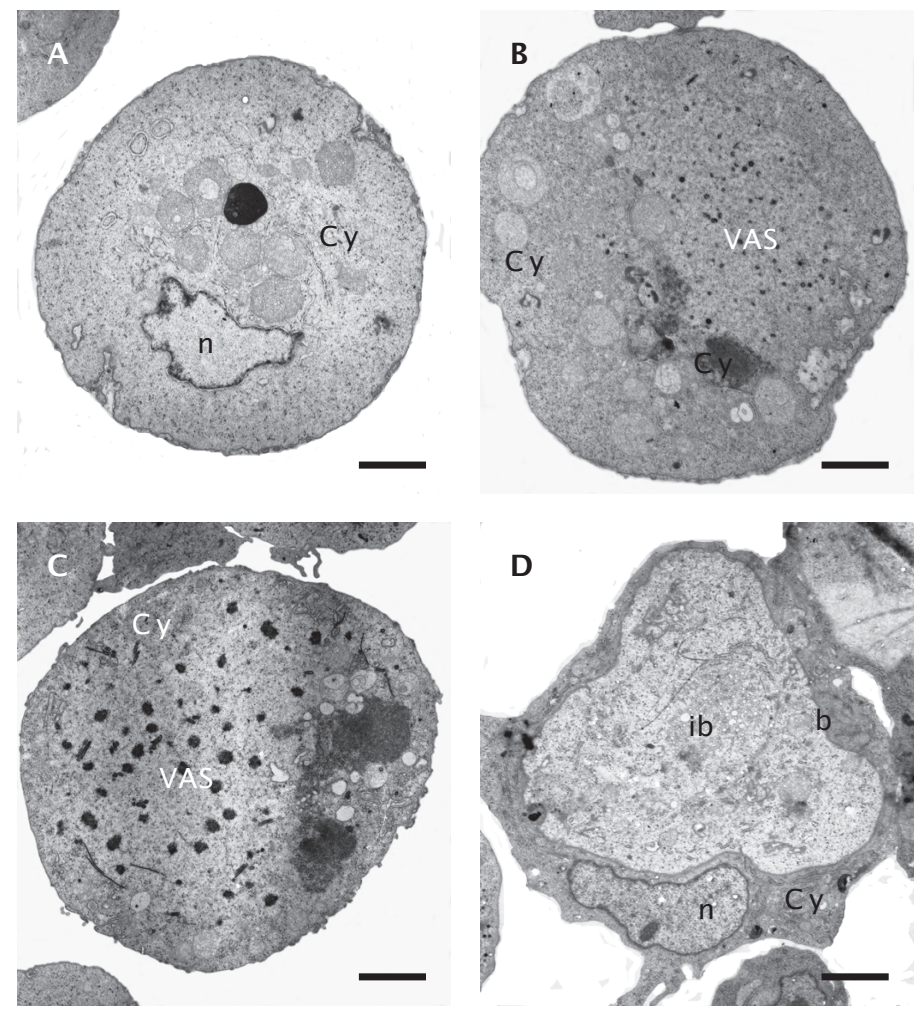

Figure 2. Detail of unproductive enlarged cells developed with abundance mitochondria without viral particles, its nucleus was marginally compressed with low content (scale bar = 1,600 nm) (A); low productive enlarged cells contained few number of viral particles within VAS, its cell lossed of nucleus (scale bar $=1,700$ ) (B); low productive cell formed tubule like structures, abundance granules, and roundspot look like viral particles within VAS (scale bar $=1,600 \mathrm{~nm})(\mathrm{C})$; unproductive IBC was developed with an intracytoplasmic inclusion body without viral particles. An intracytoplasmic inclusion body was delimited from the host-cell cytoplasm by a thin membranous boundary (scale bar $=1,800 \mathrm{~nm})(\mathrm{D}) . \mathrm{b}$ : membranous boundary, Cy: cytoplasm, ib: intracytoplasmic inclusion body, n: nucleus, VAS: viral asembly site

the inclusion body. Productive IBCs were completely described in our previously study (Mahardika \& Miyazaki, 2009). Unproductive IBCs were observed on days 6-10 after cultured RSIV in a higher numbers (0.69\%-5.26\%) compared with productive IBCs (0\%-2.35\%). However, the number of both types of IBCs was smaller than the number of enlarged cells (Table 1). Unproductive IBCs were different from productive IBCs. The host cell cytoplasm surrounded an inclusion body with the electron-lucent matrix containing abundant granules, a few mitochondria and rough endoplasmic reticulum ( $r E R$ ) (Figure 2D \& $3 A$ ). The host cell cytoplasm and nucleus were marginally compressed. An intracytoplasmic inclusion body was delimited from the host-cell cytoplasm by a thin membranous boundary, and was developed without propagation of virus particles. On the other hand, low-productive IBCs had a markedly enlarged inclusion body containing a developed VAS, many of mitochondria, smooth endoplasmic reticulum (sER) and ribosome (Figure 3B). The VAS had an electron-lucent matrix with abundant fine granules and microfilaments. The VAS allowed propagation of a small number of virus particles. As well as both types of enlarged cells, the number of both types of IBCs became decreased following time incubation (Figure $3 \mathrm{C}$ ). 

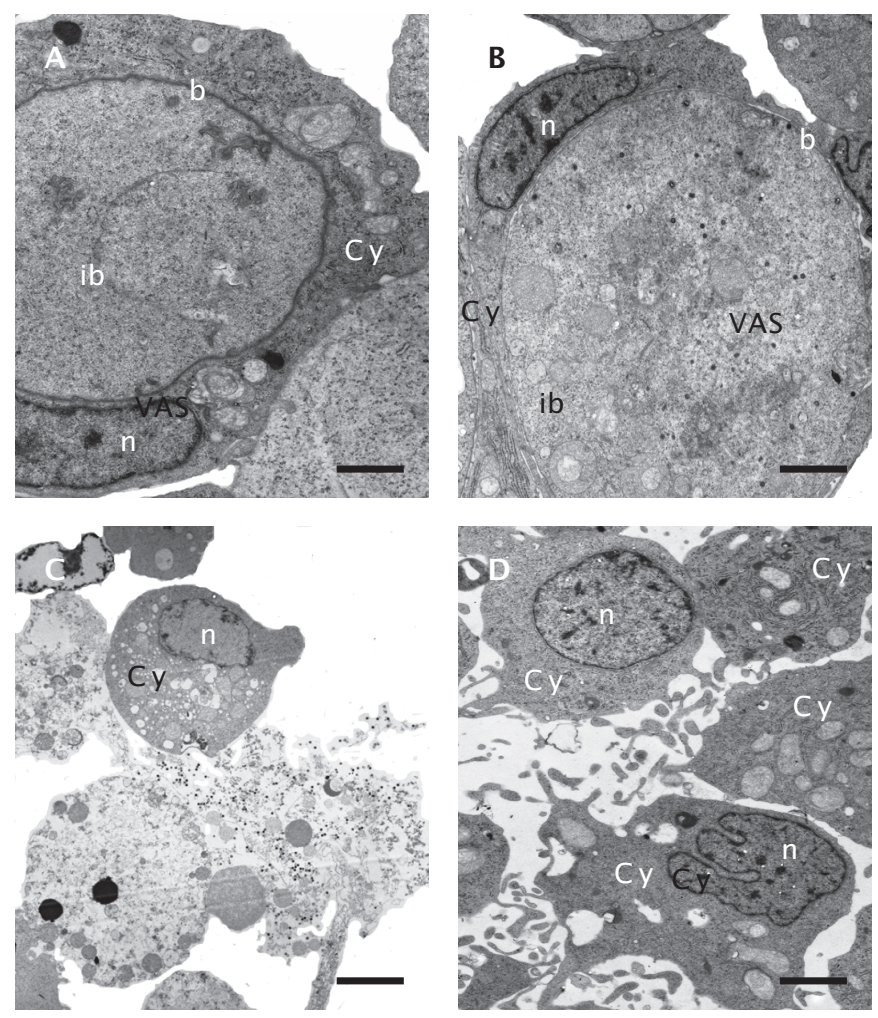

Figure 3. Detail of unproductive IBC performed intracytoplasmic inclusion body which were deliminated from the host-cell cytoplasm by thin membranous boundary. The host-cell cytoplasm contained many mitochondria, ribosome, endoplasmic reticulum and nucleus (scale bar $=1,100 \mathrm{~nm}$ ) (A); low productive IBC performed inclusion body which contained few number of viral particles within VAS and many mitochondria (scale bar $=1,500 \mathrm{~nm})(B)$; productive and unproductive enlarged cells degenerated and lysis folowing time incubation. Unproductive enlarged cell performed many vacuoles and degenerated of organelles (upper). Productive enlarged cells was lysis with viral particles remained within fragmented cell (scale bar $=2,300 \mathrm{~nm})(C)$; normal GF cells (scale bar $=850 \mathrm{~nm})(\mathrm{D})$. (Abreviation as Figure 2)

The light microscopy showed cellular enlargement and most of them were floated in cultured cells medium. Celular enlargement has been proposed to be characteristic sign of Megalocytivirus infection in vitro (Inouye et al., 1992; Nakazima \& Sorimachi, 1994; Imajoh et al., 2004). By electron microscopic examination, all enlarged cells did not allow virus propagation within intracytoplasmic VAS. RSIV also produced unproductive enlarged cells and IBCs which were not allowed virus propagation within its intracytoplasm. Fine structures of unproductive enlarged cells were different than that of the productive enlarged cells. Unproductive cell had a nucleus while produc- tive cell was lack of nucleus due to the rupture of the cell nucleus, followed by the release of the virus into the cytoplasm. Results of our study in vivo resembled results of studies by Imajoh et al. (2004) who revealed RSIVinduced enlarged cells showed two distinct characteristics as follows: one enlarged cell contained a swollen nucleus and another enlarged cell underwent severe morphological changes, such as increased cytoplasmic vacuolization, nuclear fragmentation, and formation of membrane-bound vesicle at the cell membrane. This enlarged cell contained many RSIV virions at distinct stages of development in its cytoplasm. The fragmentation and a disappear- 
ance of the nucleus appear to be naturally occurred apoptosis. Enlarged cells containing swollen nucleus or unproductive cell occured in RSIV-infected GF cells might be due to the effect of interaction between RSIV-virus component or incomplete virus or DNA with GF cells. Incomplete or component of RSIV-virus was induced the cell to enlarged and cell organeles to changed, but it failed to replicate in the nucleus and cytoplasm.

Normally, iridovirus particles entered into host cells by receptor-mediated endocytosis (Braunwald et al., 1985; Granzow et al., 1997; Zhang et al., 1999). Viral DNA synthesis in iridovirus-infected cells occurs both in the nucleus and the cytoplasm. According to this scheme, iridovirus utilizes the nucleus for early transcription and stage 1 of DNA replication. The viral DNA is then transported to the cytoplasm, where it participates in stage 2 DNA replication to form a concatemeric replication complex. The processing of concatemers to produce mature viral DNA and virus assembly also occurs in the cytoplasm (Chinchar et al., 2005). In the present study, there were lowproductive enlarged cells with the formation of a few number virus particles and tubule-like structure within intracytoplasmic VAS which might be caused by condition of cell. The virus RSIV entered cell, virus DNA was synthesized in the nuclear and subsequently transported into the cytoplasm. However, these virus DNA failed to do normal process concatemers to produce mature virions. Goorha (1982) reported the presence of enzymes that were cycloheximide in a pulse-chase experiment or treatment of the large replicative complex with alkali or S1 nuclease generated predominantly subgenomic size fragments. However, the size distribution of the fragmented DNA suggested that the breakdown of replicative complex under these conditions was not randomly distributed. Moreover, Mayer (2011) reported the binding of IFN to its receptor results in the transcription of a group of genes that code for antiviral proteins involved in preventing viral replication in that cell. As a consequence the cell will be protected from infection with a virus until the antiviral proteins are degraded, a process which takes several days. The antiviral state in IFN-treated cells results from the synthesis of two enzymes [protein 2'5' Oligo A synthetase is an enzyme that converts ATP into a unique polymer (2'5' Oligo A) containing 2'-5' phophodiester bonds, and protein kinasein that turn phosphorylates elon- gation factor elF-2] which result in the inhibition of protein synthesis. In the present study, the effect of these enzymes to inhibit virus replication in cells were found in some cells, so that I proposed the low-productive enlarged cells to be included in the productive enlarged cells. This was confirmed by a statement of Huang et al. (2006) that the area VAS and tubule-like structures are part of the viral replication. Low-productive enlarged cells were less number (2\%-15\%) from the total number of all productive enlarged cells (84\%-90\%) (Mahardika \& Miyazaki 2009; Mahardika, 2013).

IFN not only induces the production of antiviral proteins, it also has other effects on cells, some of which indirectly contribute to the ability of the host to resist or recover from a viral infection (Mayer, 2011). In the present study, IFN might contribute in inhibit RSIV-infected GF cells resulting on some GF cells remain to proceed on the bottom of the flask.

As well as unproductive enlarged cells, unproductive IBCs also found in RSIV-infected GF cells. Why had IBCs appeared in vivo studies not been solved?. Two statements that notice, the generation of IBCs represents the engulfment of infected cells by neighboring cells (apoptosis process) (Imajoh et al., 2004) or entosis process (Overholtzer et al., 2007). The unproductive and low-productive IBCs were also found in RSIV-infected cells, in vivo (Mahardika et al., 2004; Miyazaki, 2007) which suggested to be cells of the macrophage/ monocyte lineage (Chinchar et al., 2005).

\section{CONCLUSION}

RSIV-infected GF cells revealed four types of cells i.e. productive enlarged cells and productive IBCs which were allowing propagation of virus particles within its cytoplasm, and unproductive enlarged cells and IBCs without virus particles.

The unproductive and low-productive enlarged cells and IBCs were the result of RSIVinfected GF cells which failed to produce virus particles due to incapacity of RSIV virus itself and or the ability of GF cells to inhibit virus multiplication within VAS.

\section{REFERENCES}

Braunwald, J., Nonnenmacher, H., \& TripierDarcy, F. (1985). Ultrastructural and biochemical study of frog virus 3 uptake by BHK-21 cells. J. Gen.Virol., 66, 283-293. 
Chinchar, V.G., Essbauer, S., He, J.G., Hyatt, A., Miyazaki, T., Seligy, V., \& Williams, T. (2005). Family Iridoviridae. p. 145-162. In Fauquet, C.M., Mayo, M.A., Maniloff, J., Desselberger, U., \& Ball, L.A. (Eds.). Virus Taxonomy. Classification and Nomenclature of Viruses. Eighth Report of the International Committee on the Taxonomy of Viruses. Academic Press, San Diego.

Chou, H.Y., Hsu, C.C.W., \& Peng, T.Y. (1998). Isolation and characterization of a pathogenic iridovirus from cultured grouper (Epinephelus sp.) in Taiwan. Fish Pathology, 33, 201-206.

Goorha, R. (1982). Frog virus 3 DNA replication occurs in two stages. Journal of Virology, 43(2), 519-528.

Granzow, H., Weiland, F., Fichtner, D., \& Enzmann, P.J. (1997). Studies of the ultrastructure and morphogenesis of fish pathogenic viruses grown in cell culture. J. Fish. Dis., 20, 1-10.

He, J.G., Wang, S.P., Zeng, K., Huang, Z.J., \& Chan, S.-M. (2000). Systemic disease caused by an iridovirus-like agent in cultured mandarin fish, Siniperca chuatsi (Basilewsky), in China. Journal Fish Disease, 23, 219-222.

Huang, X.H., Huang, Y.H., Yuan, X.P., \& Zhang, Q.Y. (2006). Electron microscopic examination of the viromatrix of Rana grylio virus in a fish cell line. Journal Virological Methods, 133, 117-123.

Imajoh, M., Sugiura, H., \& Oshima, S.I. (2004). Morphological changes contribute to apoptotic cell death and are affected by caspase- 3 and caspase- 6 inhibitors during red seabream iridovirus permissive replication. Virology, 322, 220-230.

Inouye, K., Yamano, K., Maeno, Y., Nakajima, K., Matsuoka, M., Wada, Y., \& Sorimahi, M. (1992). Iridovirus infection of cultured red seabream, Pagrus major. Fish Pathology, 27, 19-27 (in Japanese with English summary).

Mahardika, K., Zafran, Yamamoto, A., \& Miyazaki, T. (2004). Susceptibility of juvenile humpback grouper (Cromileptes altivelis) to grouper sleepy disease iridovirus (GSDIV). Disease Aquatic Organisms, 59, 1-9.
Mahardika, K., \& Miyazaki, T. (2009). Electron microscopic features of cultured grunt fin cells infected with Megalocytivirus. Aquaculture Sciences, 57, 9-18.

Mahardika, K., \& Miyazaki, T. (2010). Ultrastructural analysis of grunt fin (GF) cells treated with red seabream iridovirus (RSIV; family Iridoviridae, genus Megalocytivirus) in combinations with interferons and splenic substances. Indonesian Aquaculture Journal, 5(1), 19-28.

Mahardika, K. (2013). Electron microscopic analysis of enlarged cells derived from red seabream iridovirus (RSIV)-infected cultured grunt fin (GF) cells. Indonesian Aquaculture Journal, 8(1), 65-73.

Mayer, G. (2011). Microbiology and immunology on-line, virology section, chapter twelve: virus-host interactions. University of South Carolina School of Medicine. http:// pathmicro.med.sc.edu/mayer/vir-host 2000.htm

Miyazaki, T. (2007). Color atlas of fish histopathology. Shin-Suisan Shimbun-Sha, Tokyo. Japan, 2,220-252.

Nakajima, K., \& Sorimachi, M. (1994). Biological and physico-chemical properties of the iridovirus isolated from cultured red seabream, Pagrus major. Fish Patholology, 29, 29-33.

Nakajima, K., Inouye, K., \& Sorimachi, M. (1998). Viral diseases in cultured marine fish in Japan. Fish Pathol., 33, 181-188.

Overholtzer, M., Mailleaux, A.A., Mouneimne, G., Normand, G., Schnitt, S.J., King, R.W., Cibas, E.S., \& Brugge, J.S. (2007). A nonapoptotic cell death process, entosis, that occurs by cell-in-cell invasion. Cell, 131, 966-979.

Williams, T., Barbosa-Solomieu, V., \& Chinchar, V.G. (2005). A decade of advances in iridovirus research. Adv. Virus Res., 65, 173-248.

Zhang, Q.Y., Li, Z.Q., \& Gui, J.F. (1999). Studies on morphogenesis and cellular interactions of Rana grylio virus (RGV) in an infected fish cell line. Aquaculture, 175, 185 197. 